\title{
Physico-chemical and biological features of a drilling site in the North Sea, 1 year after discharges of oil-contaminated drill cuttings
}

\author{
R. Daan ${ }^{1}$, H. van het Groenewoud ${ }^{2}$, S. A. de Jong ${ }^{3}$, M. Mulder ${ }^{1}$ \\ ${ }^{1}$ Netherlands Institute for Sea Research, PO Box 59, 1790 AB, Texel, The Netherlands \\ ${ }^{2}$ TNO Laboratory for Applied Marine Research, PO Box 57, 1780 AB, Den Helder, The Netherlands \\ ${ }^{3}$ Dutch Ministry of Transport and Public Works, North Sea Directorate, PO Box 5807, 2280 HV Rijswijk, The Netherlands
}

\begin{abstract}
In the framework of the Paris Convention for the prevention of marine pollution, the Dutch government initiated a research programme on environmental effects of discharges of contaminated drill cuttings from platforms in the North Sea. The programme has run since 1985 and includes field surveys at drilling sites in different parts of the Dutch sector. One of the locations investigated is the former drilling site F18.9, situated on the Oyster grounds. The (abandoned) location was visited in 1988, $1 \mathrm{y}$ after the exploratory drilling ended. This paper gives a brief overview of the 1988 study at this discharge site, which was investigated again in 1990 as part of the Bremerhaven Workshop. Chemical analyses of the sediment over a transect in the residual current direction revealed a clear gradient in contamination levels, with oil concentrations ranging from 250 to $450 \mathrm{mg} \mathrm{kg}^{-1}$ dry sediment within $250 \mathrm{~m}$ and gradually decreasing to $<20 \mathrm{mg} \mathrm{kg}^{-1}$ beyond $750 \mathrm{~m}$. Barium concentrations showed a similar pattern. Subtle biological effects, indicated by the absence of a very sensitive species (Montacuta ferruginosa), were found as far as $2 \mathrm{~km}$ from the discharge site. Abundance patterns of 2 other sensitive species (Harpinia antennaria and Callianassa subterranea) suggested environmental stress to occur up to 1 or $2 \mathrm{~km}$. Within $750 \mathrm{~m}$ from the discharge site an increasing number of species, including the dominant Amphiura filiformis, appeared to decrease in abundance, successively resulting in a reduced total macrofauna abundance and species richness. Typical opportunistic species were observed more frequently only within a radius of $250 \mathrm{~m}$. An alternative measure of diversity ('relative macrofauna abundance') was introduced and its merits are discussed. It is suggested that a combination should be used of community-based parameters (e.g. species richness, relative abundance) and species-based parameters (e.g. presence of opportunistic species, absence of susceptible species) to describe the impact of pollution. In this way 7 accumulating effects were distinguished. At contamination levels $>100 \mathrm{mg}$ oil kg-1 dry sediment all defined effects occurred, whereas below $20 \mathrm{mg} \mathrm{kg}^{-1}$ the number of effects rapidly decreased.
\end{abstract}

\section{INTRODUCTION}

One of the locations investigated during the Bremerhaven Workshop was the former drilling site F18.9, situated in the Oyster grounds, in the Dutch sector of the Continental Shelf $\left(54^{\circ} 06^{\prime} 09^{\prime \prime} \mathrm{N}, 04^{\circ} 45^{\prime} 25^{\prime \prime} \mathrm{E}\right)$. Location F18.9 was drilled in May 1987 and during the drilling activities large amounts of cuttings, contaminated with adhering drilling muds, were discharged to the seabed (Table 1). Among the muds used, a considerable part consisted of 'Oil Based Muds' (OBM). Hence, the discharges included the disposal of a few hundred tonnes of oil and were therefore a significant point source of sediment pollution.

One reason for choosing the location F18.9 from numerous other drilling sites in the southern North Sea was that the location had already been investigated. In June 1988 (1 yг after the drilling activities had ceased and the platform was removed), a field survey was carried out at the location to detect the spatial distribution of contaminants around the discharge point and to assess their impact on the macrobenthic infauna. This study was performed in the framework of a research programme initiated by the Dutch Ministry of 
Table 1. Amounts of mud and cuttings (tonnes dry weight) discharged during drilling of well F18.9. From a total of $5 \mathrm{sec}-$ tions, the first 2 were drilled with water based muds; the next 2 were drilled using a low toxicity base oil $\left(17 \frac{1}{2} 2^{\prime \prime}\right.$ and $8 \frac{3}{8}$ " holes), the last section $\left(5^{7} / 8^{\prime \prime}\right)$ being a water-based mud again. Data provided by the company concerned

\begin{tabular}{|c|c|}
\hline Substance & Amount \\
\hline \multicolumn{2}{|l|}{ Minerals: } \\
\hline Lime & 8.5 \\
\hline Baryte & 275 \\
\hline Bentonite & 525 \\
\hline \multicolumn{2}{|l|}{ Polymers: } \\
\hline Carboxymethylcellulose & 25 \\
\hline Others & 0.9 \\
\hline \multicolumn{2}{|l|}{ Salts: } \\
\hline $\mathrm{KCl}$ & 40 \\
\hline $\mathrm{NaCl}$ & 4.5 \\
\hline $\begin{array}{l}\mathrm{CaCl}_{2} \\
\widetilde{\mathrm{KI}}\end{array}$ & 4.5 \\
\hline \multicolumn{2}{|l|}{ Base oil: } \\
\hline Low toxic ${ }^{a}$ & 300 \\
\hline \multicolumn{2}{|l|}{ Emulsifier: } \\
\hline Fatty acids based & 6 \\
\hline Polyamide based & 10 \\
\hline \multicolumn{2}{|l|}{ Viscosifier: } \\
\hline Amine treated bentonite & 8.5 \\
\hline \multicolumn{2}{|l|}{ Cuttings: } \\
\hline Natural rock & 2000 \\
\hline${ }^{a}$ Amount includes also oil in & \\
\hline
\end{tabular}

Transport and Public Works (North Sea Directorate). The aim of this programme is to detect to what extent discharges of contaminated drill cuttings affect the composition and functioning of the natural benthic fauna, and how long such effects can be observed after termination of the drilling activities. The development and standardisation of suitable monitoring techniques was also part of the study. The results of the 1988 study on short-term effects at F18.9 are described in detail in reports on the chemistry by Groenewoud (1991) and on

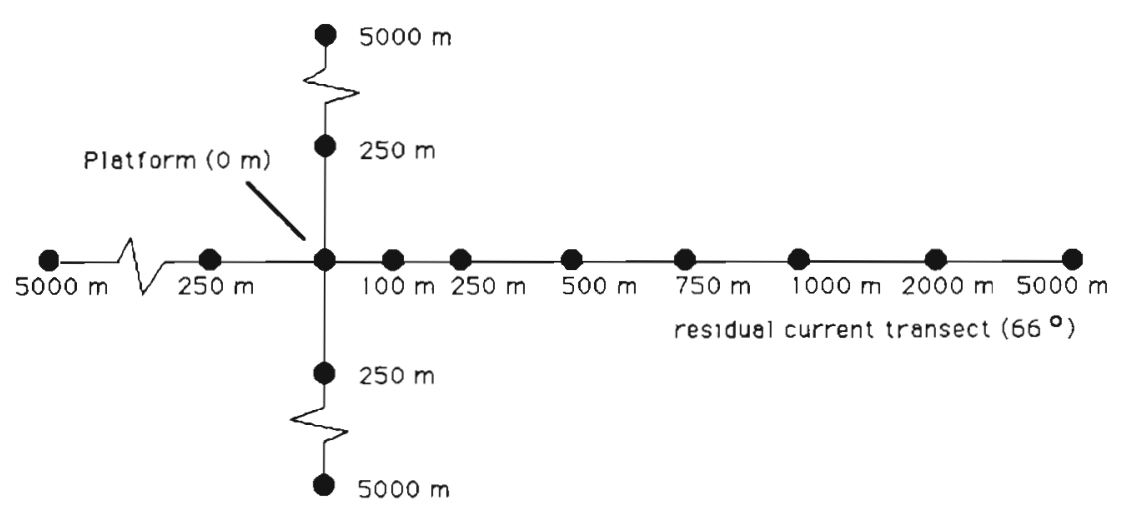

Fig. 1. Positions of the sampled stations (distance to platform in $\mathrm{m}$ ) the biological effects by Daan et al. (1990). The present paper gives a brief overview of the 1988 study at F18.9.

\section{METHODS}

Positioning. Location F18.9 was abandoned after the explorative drillings were terminated in 1987 and the rig was not replaced by a production platform, so the discharge site had to be established using Decca positioning. As the RV 'Holland' is not equipped with a dynamic positioning system, the ship was anchored at each station before sampling started. Consequently the accuracy of position fixing was to within 50 to $200 \mathrm{~m}$ of the exact station positions. Because of this lack of precision in position finding the sampling stations may be considered as points along a continuum rather than as strictly defined sites.

Sampling. Around the discharge site a cross-shaped transect was sampled including four $250 \mathrm{~m}$ and four $5000 \mathrm{~m}$ stations. In the residual current direction $\left( \pm 66^{\circ}\right)$ another 6 stations were sampled (Fig. 1).

Eight $0.2 \mathrm{~m}^{2}$ Van Veen grabs were taken at each sampling station. From each grab sample 2 small cores $(28 \mathrm{~mm}$, depth $10 \mathrm{~cm}$ ) were taken for grain-size, oil and barium analyses. These samples were pooled and immediately frozen at $-20^{\circ} \mathrm{C}$ for later analysis. After subsampling for chemical analyses, the remaining sediment was sieved (mesh size $1 \mathrm{~mm}$ ) and the residual macrofauna was preserved in a $6 \%$ neutral formaldehyde solution.

Laboratory analyses. Oil analyses were performed using the gas chromatograph mass spectrometer technique. Concentrations of the fractions of alkanes $\left(\mathrm{C}_{9}\right.$ to $\mathrm{C}_{30}$ ), unidentified complex matter (UCM) and 'other components' were quantified. The sum of these fractions is defined as the total oil concentration. Barium concentrations were determined by means of inductive coupled plasma-atomic-emission spectrometry. Methods are described in detail by Groenewoud (1991). Data on oil and barium concentrations are only available for 7 stations at the residual current transect.

The macrofauna samples were stained with Rose Bengal and sorted under a stereo microscope Then, molluscs, crustaceans, polychaetes and echinoderms were identified and counted to species level. Remaining taxa were not further identified and only recorded at higher taxonomic levels.

Statistical procedures. Logit regression was used to detect significant gradients in the frequency of 
occurrence of individual species (see Jongman et al. 1987). The method is based on presence-absence data for species in individual samples. The analysis was done only for identified species for which at least 20 specimens were found.

A second statistical procedure was performed to determine the distance over which effects of pollution could be detected on the whole macrobenthic community. The method is based on the mean 'relative abundance' of all identified species at each station. Computation of the relative abundance is based on a ranking procedure. For each species the mean density is considered at each of the $(n)$ analysed stations. A rank is attributed to each species for each station, i.e. the rank is 1 for the station with the lowest density and $n$ for the station with the highest density. If any densities are equal, they are given the average of the tied ranks. When this procedure was completed for all species a mean rank was computed for each station. Differences in mean ranks were then tested for significance by analysis of variance.

\section{RESULTS}

\section{Grain-size distribution}

The sediment structure appeared to be quite homogeneous in the area. The sediment is fine, the silt fraction (grain-size $<63 \mu \mathrm{m}$ ) ranging from 15 to $20 \%$ and the total fraction $<80 \mu \mathrm{m}$ ranging from 40 to $50 \%$. The two $5000 \mathrm{~m}$ stations at the perpendicular transect were somewhat different in the sense that the fine sand fraction ( 80 to $125 \mu \mathrm{m}$ ) was reduced by 10 to $15 \%$ in favour of the course sand fraction $(>125 \mu \mathrm{m})$.

\section{Chemical characteristics}

A clear gradient was found in barium content of the sediment beyond $250 \mathrm{~m}$ in the residual current direction, and oil concentrations showed roughly a similar

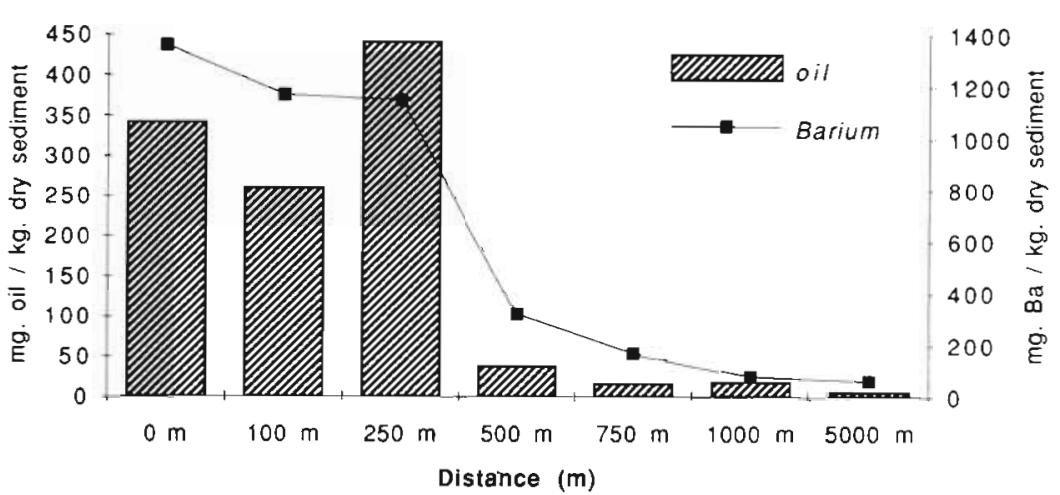

Fig. 2. Oil and barium concentrations of the sediment along the residual current transect.

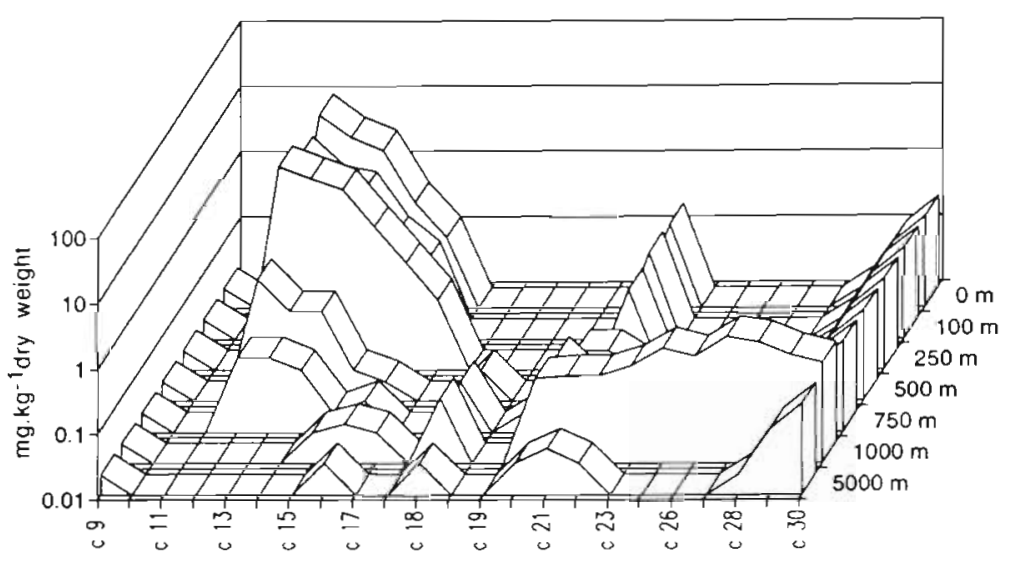

Fig. 3. Composition of alkanes $\left(\mathrm{C}_{9}\right.$ to $\left.\mathrm{C}_{30}\right)$ of oil in the sediment along the residual current transect

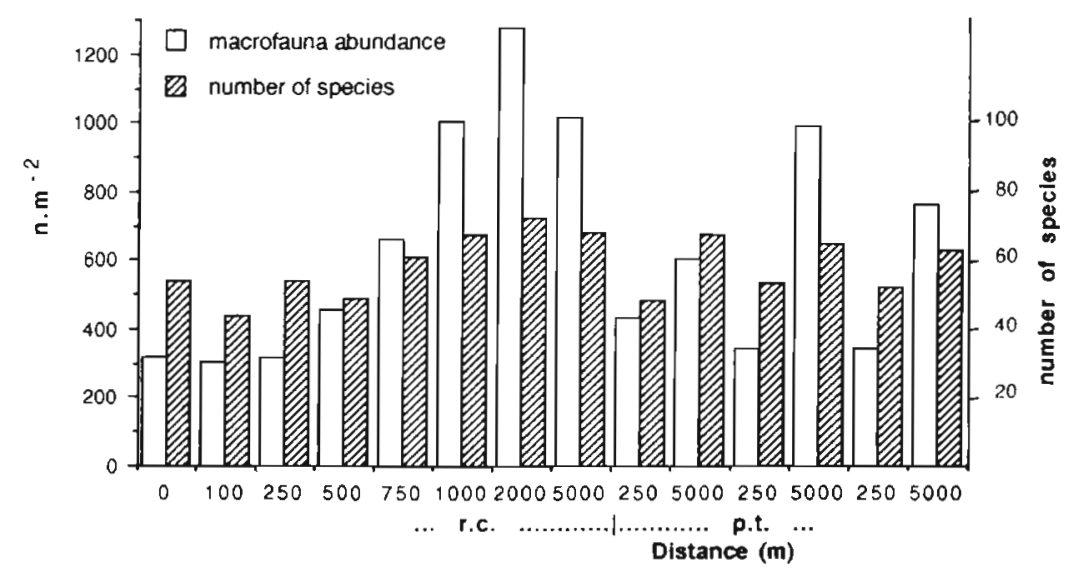

Fig. 4. Total macrofauna abundance and species richness along the residual current transect (r.c.) and perpendicular transects (p.t.)

trend (Fig. 2). Within $250 \mathrm{~m}$ the concentrations were more or less similar. A gradient within this radius was possibly masked by inaccurate positioning. Moreover, because of the lack of precision in position finding it is not known whether the marked difference of barium and oil concentrations between $250 \mathrm{~m}$ and $500 \mathrm{~m}$ is realistic. The actual distances between the stations 


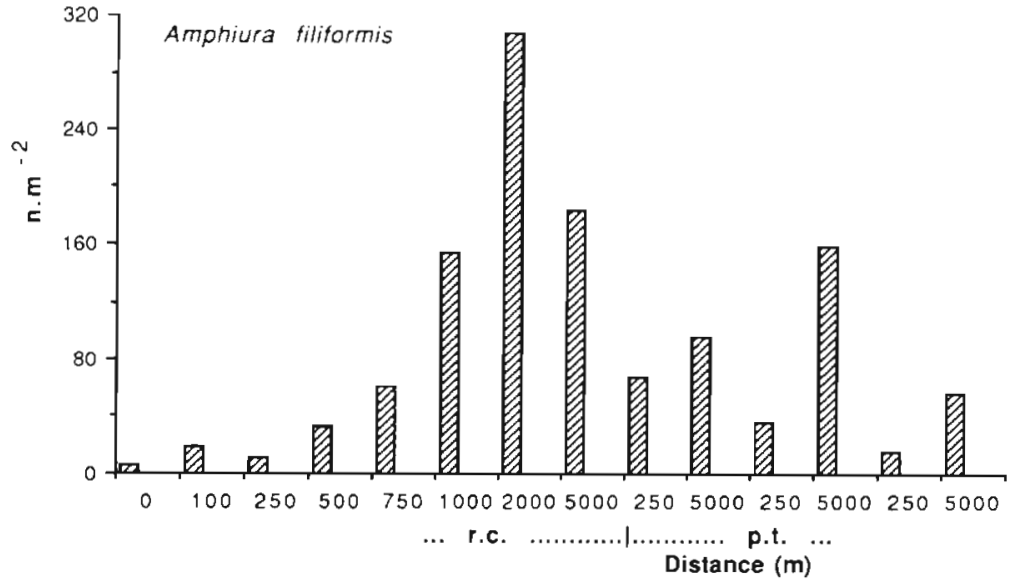

Fig. 5. Amphiura filiformis. Abundance pattern of the dominant species along the residual current (r.c.) and perpendicular (p.t.) transects

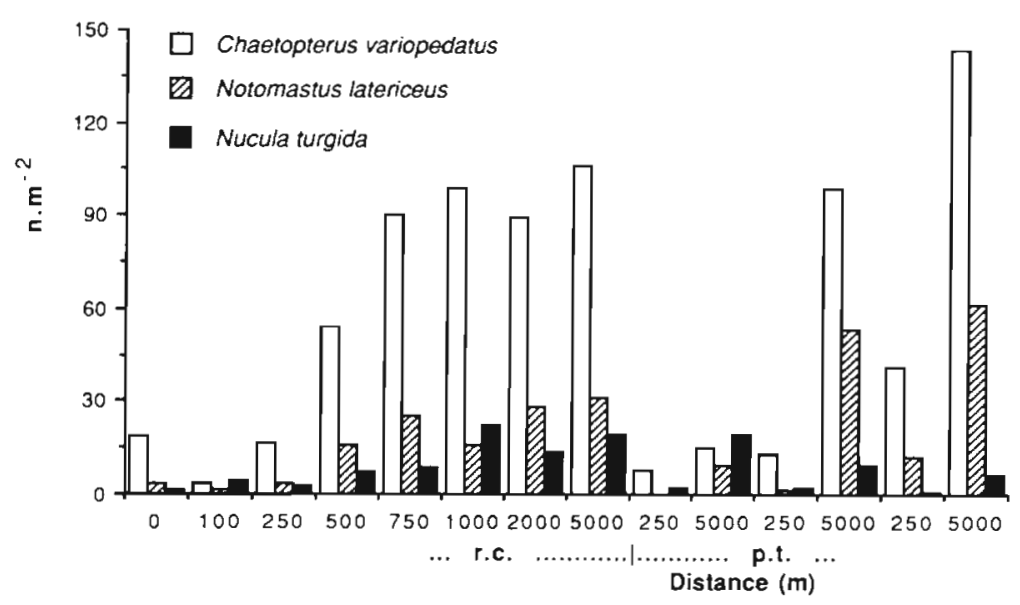

Fig. 6. Density patterns of 3 abundant species along the residual current (r.c.) and perpendicular (p.t.) transects

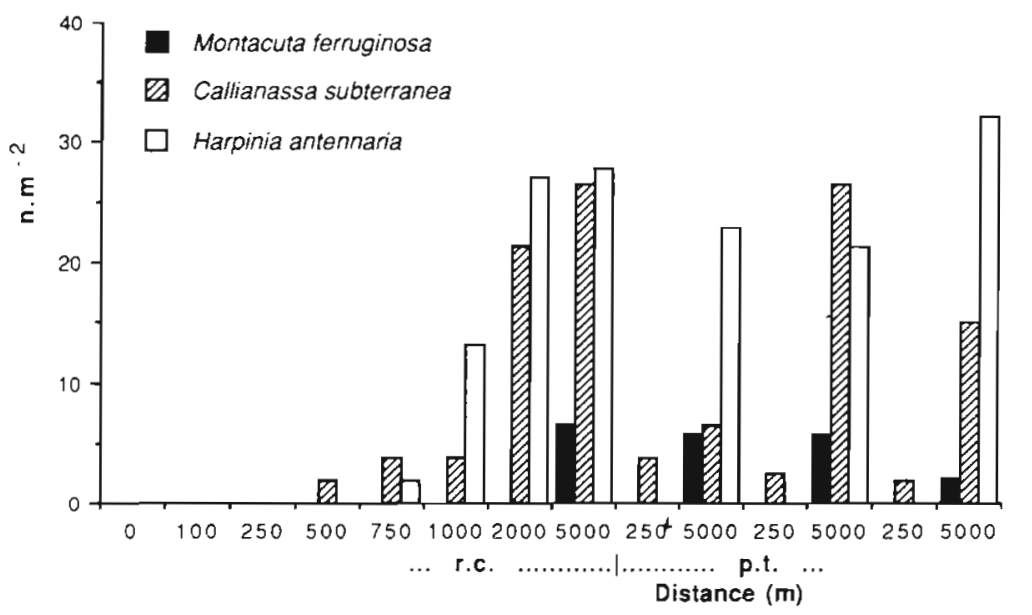

Fig. 7. Abundance patterns of 3 sensitive species along the residual current (r.c.) and perpendicular (p.t.) transects may have been greater. The composition of the alkanes in the oil detected was quite consistent up to $750 \mathrm{~m}$ from the drilling site (Fig. 3). At the $1000 \mathrm{~m}$ station, the lack of short C-chains $\left(C_{11}\right.$ to $\left.C_{14}\right)$ and an unexpected peak of long $C$-chains $\left(C_{19}\right.$ to $\left.C_{30}\right)$ indicated the presence of oil not originating from the OBM discharged. Detailed data on physico-chemical features are presented by Groenewoud (1991).

\section{Macrofauna composition}

A total of 107 macrobenthos species were identified from 14 stations. The number of species found at each station varied between 44 and 72 (Fig. 4). At the residual current transect the numbers were low within $500 \mathrm{~m}$ (44 to 54) and tended to increase beyond $750 \mathrm{~m}$ (63 to 72 ). At the $750 \mathrm{~m}$ station the number was intermediate (61). Numbers of species found at the perpendicular transects indicated similar gradients in species richness.

The polychaete Lumbrineris latreilli and juvenile specimens of the echinoderm Amphiura filiformis dominated the macrofauna by number. Together they accounted for 10 to $40 \%$ of the macrofauna in the area. The latter species in particular showed obvious lower densities within $750 \mathrm{~m}$ on each transect when compared to the densities at the corresponding $5000 \mathrm{~m}$ reference sites (Fig. 5). A similar trend was found in most other relatively abundant species $(\geq 10$ specimens $\mathrm{m}^{-2}$ ). More than $50 \%$ of the species declined in densities within $750 \mathrm{~m}$ from the platform. Examples of density patterns of 3 abundant species are shown in Fig. 6. Logit regression, applied to 46 species for which at least 20 specimens were found, confirmed that gradients in frequency of occurrence were significant ( $5 \%$ level) in 21 species (Table 2). A few species the crustaceans Harpinia antennaria and Callianassa subterranea) seemed to increase in abundance even beyond $1000 \mathrm{~m}$, and the mollusc Montacuta ferruginosa was found in $50 \%$ of the 
Table 2. List of species showing a significant gradient in frequency of occurrence (logit regression). Sign of the gradient $(+/-)$ and significance level are indicated. +: Increasing frequency away from the location; -: decreasing frequency away from the location

\begin{tabular}{|lcc|}
\cline { 2 - 3 } & Sign & Signif. level (\%) \\
\hline Harmothoe longisetis & + & 0.5 \\
Anaitides groenlandica & - & 5 \\
Glycinde nordmanni & + & 5 \\
Lumbrineris latreilli & + & 5 \\
Lumbrineris fragilis & + & 1 \\
Spiophanes bombyx & + & 0.1 \\
Chaetopterus variopedatus & + & 0.5 \\
Chaetozone setosa & + & 0.5 \\
Notomastus latericeus & + & 0.1 \\
Heteromastus filiformis & + & 0.1 \\
Owenia fusiformis & + & 5 \\
Nucula turgida & + & 0.1 \\
Montacuta ferruginosa & + & 0.1 \\
Mysella bidentata & + & 1 \\
Abra alba & + & 5 \\
Cingula nitida & + & 5 \\
Cylichna cylindracea & + & 5 \\
Callianassa subterranea & + & 0.1 \\
Diastylis bradyi & + & 5 \\
Harpinia antennaria & + & 0.1 \\
Amphiura filiformis & + & 0.1 \\
Echinocardium cordatum & + & 5 \\
& & \\
\hline
\end{tabular}

samples at all $5000 \mathrm{~m}$ stations (Fig. 7). One species, the polychaete Anaitides groenlandica, showed an opposite trend and occurred in significantly higher densities within $250 \mathrm{~m}$ of the discharge point (Fig. 8). The same pattern was found in the polychaete Capitella capitata, but was not statistically significant as the number of specimens found was too small (14).

In accordance with the abundance patterns described above for most of the individual species, total macrofauna abundance was considerably lower at stations $\leq 500 \mathrm{~m}$ (300 to 450 ind. $\mathrm{m}^{-2}$ ) than at stations $\geq 1000 \mathrm{~m}(600$ to 1300 ind. $\mathrm{m}^{-2}$ ). The $750 \mathrm{~m}$ station was intermediate (Fig. 4). Within $250 \mathrm{~m}$ no further gradual decrease to the $0 \mathrm{~m}$ station was observed.

The relative macrofauna abundance at the 14 stations sampled clearly illustrates the lower densities of most species at all stations $\leq 500 \mathrm{~m}$ from the discharge point (Fig. 9). Analysis of variance and an additionally applied Least Significant Difference test (LSD-test; Sokal \& Rohlf 1981) revealed that the relative abundance was significantly lower at stations within $500 \mathrm{~m}$ than at stations $\geq 750 \mathrm{~m}$ from the discharge point.

\section{Dose-effect relationships}

So far, the biological features around F18.9 have been described in terms of gradual changes in faunal abundance along the sampled transect. Spatial gradients in abundance patterns (on species level or community level) may be implicitly assumed to represent an effect of the contaminated material discharged. It is in general not possible, however, to quantify such effects reliably, because of the natural variability in the abundance of species within the area investigated. We are compelled, therefore, to compare contamination levels (expressed as mg oil $\mathrm{kg}^{-1}$ dry sediment) and biological effects in a qualitative way. Although the effects that were identified are generally not independent of each other, accumulation of effects may serve as the most suitable response variable. Fig. 10 shows that the number of measurable effects increased with oil concentrations in the sediment. At contamination levels beyond $100 \mathrm{mg}$ oil $\mathrm{kg}^{-1}$ dry sediment, all defined effects were consistently observed. At levels between 20 and $100 \mathrm{mg} \mathrm{kg}^{-1}$ most effects were observed, but opportunist species hardly seemed to increase in abundance. In some respects the effects at these concentrations were less severe than at concentrations higher than $100 \mathrm{mg} \mathrm{kg}{ }^{-1}$, e.g. the reduction in densities of dominant (Amphiura filiformis) and abundant species was less pronounced (Figs. 5 \& 6). Below $20 \mathrm{mg} \mathrm{kg}^{-1}$ the number of effects rapidly decreased. Only some species that seemed to be particularly susceptible to the kind of pollution involved occurred in reduced numbers.

\section{DISCUSSION}

Numerous studies have shown biological effects due to discharges of OBM contaminated drill cuttings on

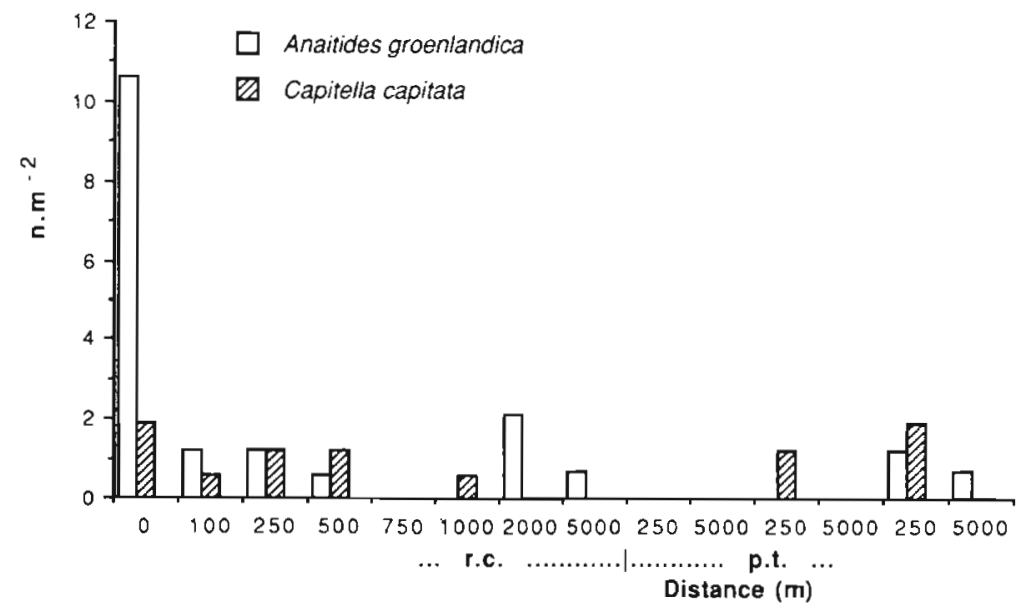

Fig. 8. Abundance patterns of 2 opportunistic species along the residual current (r.c.) and perpendicular (p.t.) transects 


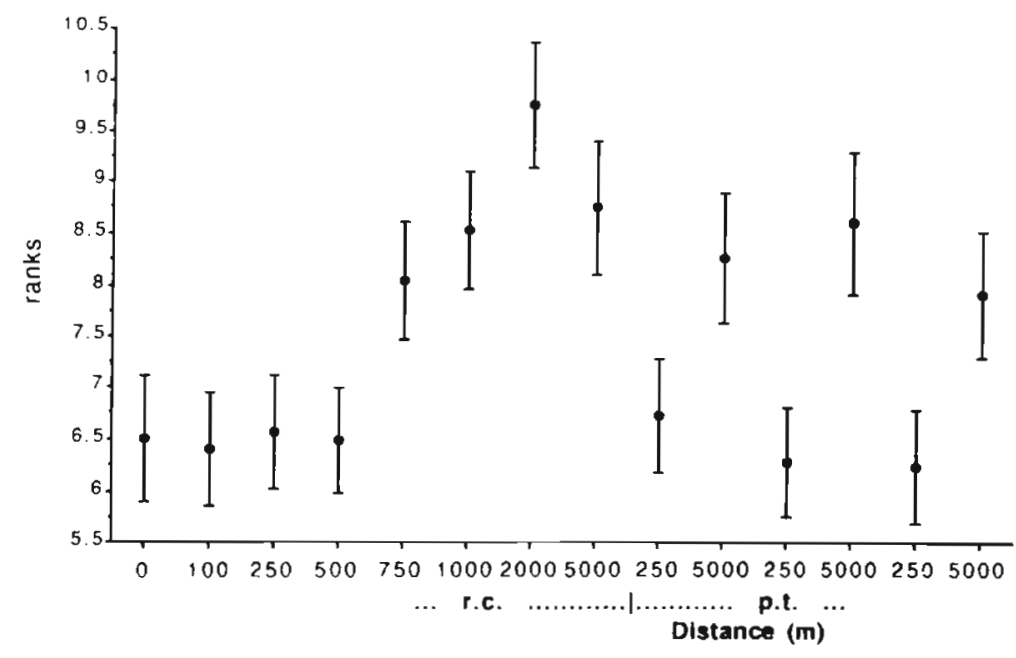

Fig. 9. Pattern of relative macrofauna abundance along the residual current (r.c.) and perpendicular (p.t.) transects. Centre points are mean ranks and vertical bars give $95 \%$ contidence lumits

the seabed. Field surveys at OBM drill sites in all sectors of the North Sea have revealed that such discharges affect the faunal composition of the sediment (e.g. Gray 1982, Addy et al. 1984, Davies et al. 1984, 1989, Matheson et al. 1986, Kingston 1987, Mulder et al. 1987, 1988, Reiersen et al. 1989, Daan et al. 1990, 1991, Gray et al. 1990).

The criteria used to decide whether biological effects of sediment pollution are demonstrable are numerous, varying from community-based parameters (e.g. species richness, diversity or equitability) to species-based parameters (e.g. dominance of opportunistic species, absence of susceptible species). It is not only the use of different criteria, but also the differences in interpretation of data, that causes controversy concerning the extent of impact zones around drilling sites. For example, in the heavily polluted area around the Statfjord oil field (Norwegian sector), the maximal range of effects on the macrofauna was estimated as 500 to $1000 \mathrm{~m}$ in 1984 (Davies et al. 1984, Matheson et al. 1986, Kingston 1987), but in 1986 Reiersen et al. (1989) found a change in macrofauna out to $5000 \mathrm{~m}$. Although additional discharges in the intervening years may have increased the area of environmental perturbation, this cannot expiain compleiely the discrepancy between the 2 estimates. Differences of opinion about the interpretation of field data seem to play a major role.

It seems plausible that the intensity of effects will decrease with decreasing intensity of the stressor. This implies that the detection of effects will become more difficult and less reliably quantifiable as the distance to the point source of pollution increases. Therefore, it is advisable to use a combination of criteria to qualitatively assess the impact of pollution. Gray et al. (1990), who clearly demonstrated effects in terms of changed fauna composition up to $2000-3000 \mathrm{~m}$ from the Ekofisk

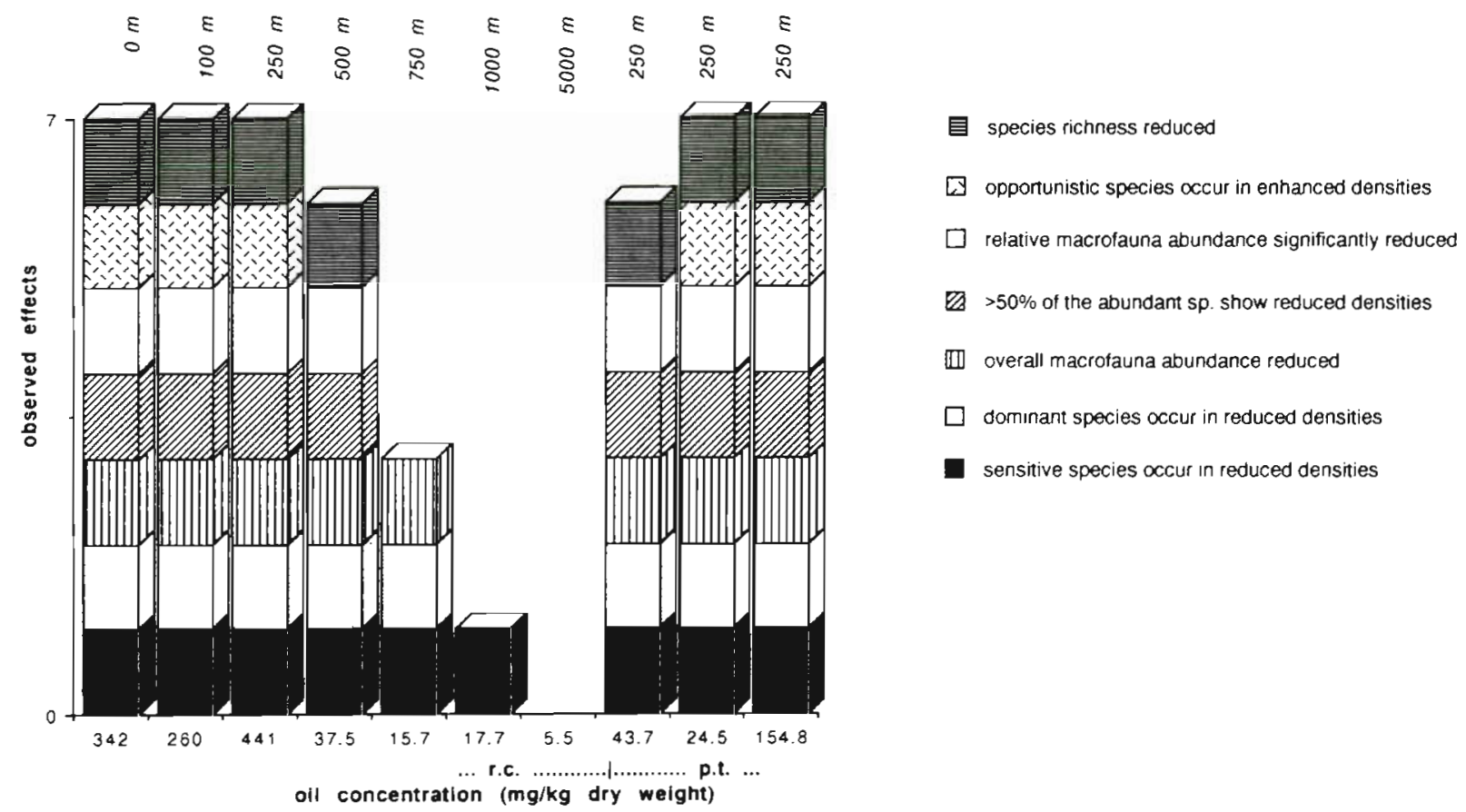

Fig. 10. Observed effects around F18.9 at different levels of sediment contamination 
oil field, suggested that one of the initial effects of disturbance is the eradication of some 'rare' species. The authors did not explain why rare species should be more susceptible to disturbance than abundant species, but they may have assumed implicitly that rare species are generally living on the border of their ecological range and hence tolerate less additional stress. This indeed seems plausible, but it is questionable whether species that are found only a few times in samples should be considered rare in the true sense of the word. We believe that most species considered as 'rare' are only rare compared to other species, which are more or less abundant by nature. Nevertheless, our data support the idea that absence or reduced abundance of some susceptible species is the most sensitive indication of environmental stress. Up to $1000 \mathrm{~m}$, at $16 \mathrm{mg}$ oil $\mathrm{kg}^{-1}$ sediment, Harpinia antennaria and Callianassa subterranea were found in significantly reduced numbers and Montacuta ferruginosa was even absent out to $2000 \mathrm{~m}$ in the residual current direction, whereas it was found to be present at all $5000 \mathrm{~m}$ stations. There is, indeed, much evidence that species belonging to the genus Montacuta are extremely sensitive to the toxic effect of oil contamination. During 9 surveys of 4 other OBM locations in the Dutch sector $M$. ferruginosa was found to be consistently absent in the vicinity of platforms and in 4 cases the species was found exclusively or almost exclusively at $\geq 3000 \mathrm{~m}$ from the discharge site and furthermore in densities of $\geq 20$ ind. $\mathrm{m}^{-2}$ (see Mulder et al. 1987, 1988, Daan et al. 1990,1991 ). On the other hand, at 2 locations where only WBM (water based muds) were used, the species did not show any sign of a gradient in abundance pattern. The sensitivity of Montacuta is also supported by the data presented by Gray et al. (1990), who found $M$. substriata abundant at Ekofisk only outside a radius of 2 to $3 \mathrm{~km}$, whereas it was absent within $500 \mathrm{~m}$. At Eldfisk $M$. substriata was found only outside a radius of 1 to $2 \mathrm{~km}$. If we consider oil contamination as a major stress factor affecting the distribution pattern of Montacuta, it is concluded that $M$. ferruginosa seems to suffer from environmental stress out to $2 \mathrm{~km}$ from the discharge point at F18.9 (residual current direction; Fig. 7).

The abundance patterns of Harpinia antennaria and Callianassa subterranea too are not likely to be explained by accidental natural variation. During surveys at other drill sites in the Dutch sector, where these species occurred in densities sufficiently high to discern a pattern, $H$. antennaria decreased in density towards the platform at 5 OBM locations and exhibited no gradient at 2 WBM locations. C. subterranea showed decreasing densities towards the platform at 5 OBM locations and exhibited no gradient at 1 OBM and 1 WBM location (see Mulder et al. 1987, 1988, Daan et al. 1990,
1991). Hence, both species may be considered susceptible to oil contamination and, at F18.9, suffering from environmental stress up to 1 to $2 \mathrm{~km}$ from the discharge point (residual current direction; Fig. 7).

At the stations $750 \mathrm{~m}$ and $500 \mathrm{~m}$ from the drilling site an increasing number of species appeared to decline in abundance, including some species that were abundant $\left(\geq 10\right.$ ind. $\mathrm{m}^{-2}$ ) or even dominant by nature (Amphiura filiformis). As a result a gradual reduction could be observed in the total macrofauna abundance, relative abundance and species richness. No species were found that increased in density at the moderate contamination levels found in this zone. This was in contrast to the scenario outlined by Gray et al. (1990), who suggested that (moderate) disturbance could confer an advantage on some species, which can exploit the resource with reduced competition from less tolerant species and consequently increase in abundance. Indeed, their data show a dramatic increase in abundance of several species in the polluted area, e.g. the polychaete Chaetozone setosa. At F18.9 we found no such increase, but a decrease in abundance of this species. A possible explanation for these conflicting results may be that their data originate from locations where platforms are present. The presence of platforms keeps fisheries activities at a distance, which have adverse effects on some benthic species, and are thus beneficial to the local abundance of those species, when they are not extremely sensitive to OBM contamination. The observations of Levell et al. (1989) in the Thistle oil field (UK sector) and of Davies et al. (1984) in the Beatrice oil field (also UK sector) support this idea. Within $1000 \mathrm{~m}$ they found a dramatic increase of $C$. setosa, followed by a steep decline in the very close vicinity of the platform. At location K12a in the Dutch sector, where a platform is present, we found a similar abundance pattern of $C$. setosa during annual surveys between 1985 and 1988 (Mulder et al. 1987, 1988, Daan et al. 1990). The species always tended to increase abundance within $1000 \mathrm{~m}$ from the platform,

\footnotetext{
- In this context it is worth noting that members of the genus Montacuta are commensals of echinoids (e.g. Gage 1966) and $M$. ferruginosa generally lives attached to the spines of Echinocardium cordatum. This may raise the question how the distribution of $E$. cordatum was related to that of $M$. ferruginosa. In the numerical abundance patterns of the 2 species was no clear relationship, but it seems plausible that the presence of $M$. ferruginosa depends on the presence of larger specimens of E. Cordatum. Data on the size distribution of $E$. cordatum are not available, but if this is true, it is conceivable that $M$. ferruginosa might be indirectly indicative of sediment contamination and that, in fact, the absence of larger specimens of the host species is the direct response. This idea is supported by the results of experiments in mesocosms, where adult E. cordatum proved to be strongly sensitive to sediment contamination
} 


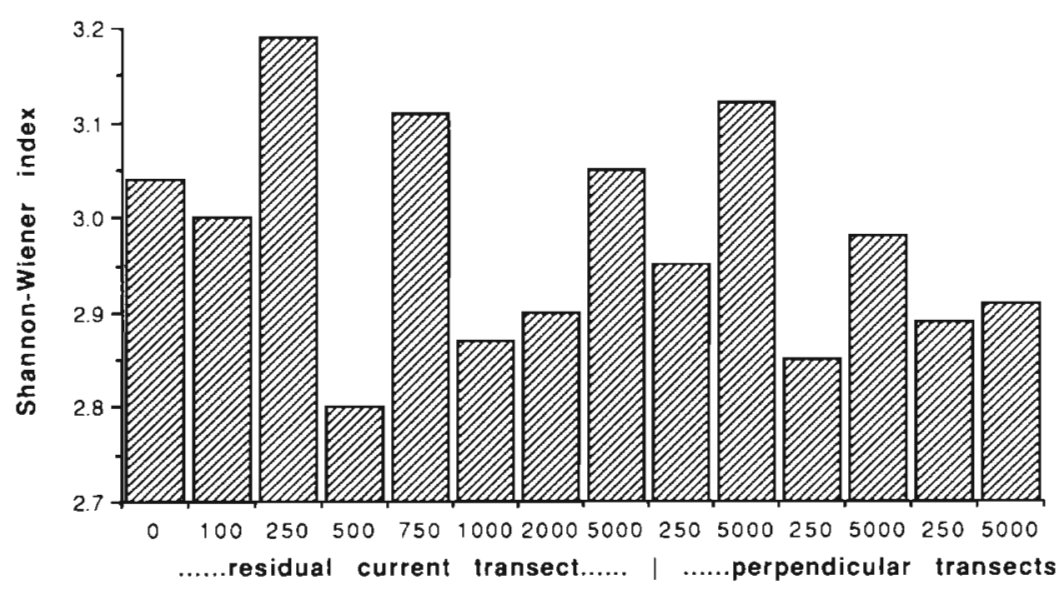

Fig. 11. Diversity at the residual current transect and at perpendicular transects: Shannon-Wiener index using $\log _{\mathrm{e}}$-transformed data

authors calculated these indices for stations around drill site L4-a (also in the Dutch sector) and found a dramatic increase of diversity in the immediate vicinity of the platform due to the absence of the dominant species, Amphiura filiformis. When this species was excluded from the calculations no trend in diversity could be found. We used relative macrofauna abundance as an alternative measure of diversity. The method has several advantages although a handicap of the parameter may be that its attributed value is always relative and depends on the number of stations sampled. It provides an illustrative graphic presentation of an overall shift in fauna

but abruptly disappeared within $50 \mathrm{~m}$, at contamination levels beyond $10000 \mathrm{mg}$ oil $\mathrm{kg}^{-1}$ dry sediment. At F18.9, however, where no platform is present, any positive effect of the absence of fishing activity is absent, and this possibly could explain why the abundance of this low-sensitive species gradually decreased with increasing contamination.

An increase in abundance of typical opportunists was only observed within $250 \mathrm{~m}$. Two species (Anaitides groenlandica and Capitella capitata) were found almost exclusively within this area, however, without becoming dominant. A groenlandica has been shown to thrive under enrichment by organic pollution (Pearson et al. 1983) and C. capitata is well known to be abundant under gross organic enrichment, including areas affected by oil pollution (e.g. Pearson \& Rosenberg 1978, Gray 1982, Davies et al. 1984, Levell et al. 1989). Both species are relatively rare in undisturbed sediment and their more or less frequent occurrence within $250 \mathrm{~m}$ from the discharge site indicates pollution within this zone. This supports the statement that opportunistic species need not necessarily be abundant or even dominant to indicate environmental stress. The fact that the densities of A. groenlandica and C. capitata were only slightly enhanced at contamination levels of 250 to $450 \mathrm{mg}$ oil kg-1 dry sediment suggests (in accordance with Gray et al. 1990) that colonisation by opportunists occurs late in the sequence of responses to stressors. Dominant occurrence of such species can only be expected under grossly polluted conditions around platforms where several wells have been drilled.

Traditional methods to quantify diversity were not used in this study. Commonly used indices like the Shannon-Wiener index and the Brillouin index have been shown to be very sensitive to the abundance of one dominant species (Mulder et al. 1988). The latter abundance and differences in mean relative abundance are statistically verifiable. Moreover, in contrast to traditional diversity indices, all species have an equal share in the computation of mean relative abundance. As a consequence, its attributed value is not disproportionally affected by the abundance of one species. In order to compare the sensitivity of the method with a usual measure of diversity we calculated Shannon-Wiener indices for the fauna at the stations around F18-9. The results (Fig. 11) illustrate that the index seems to fluctuate within a rather narrow range of 2.8 to 3.2 and does not show any pattern that is related to distance from platform or oil concentration (Fig. 2). Gray (1989) and Gray et al. (1990) concluded that a significant reduction in diversity may be a final response to stressors and should be expected only in a severely disturbed environment. We agree with their view, but we suggest that relative abundance may serve as a more sensitive measure of diversity than traditional indices.

Acknowledgements. This project was initiated by the Dutch Ministry of Transport and Public Works and co-financed by the Ministry of Housing, Physical Planning and the Environment (VROM) and the State Supervision of Mines of the Ministry of Economic Affairs. Emission data of F18.9 were provided by J Marquenie of the Nederlandse Aardolie Maatschappij (NAM). Laboratory analyses, including sorting macrofauna samples and species identification, were largely performed by W. E. Lewis.

\section{LITERATURE CITED}

Addy, J M., Hartley, J. P., Tibbets, P. J. C. (1984). Ecological effects of low toxicity oil based mud drilling in the Beatrice oilfield. Mar. Pollut. Bull. 15: 429-436

Daan, R., Lewis, W. E., Mulder, M. (1990). Biological effects of discharged oil-contaminated drill cuttings in the North 
Sea. Boorspoeling III-IV, NIOZ-rapport 1990-5. NIOZ, Texel, The Netherlands, $79 \mathrm{pp}$.

Daan, R., Lewis, W. E., Mulder, M. (1991). Biological effects of washed OBM drill cuttings discharged on the Dutch Continental Shelf. Boorspoeling V, NIOZ-rapport 1991-8. NIOZ, Texel, The Netherlands, $33 \mathrm{pp}$.

Davies, J. M., Addy, J. M., Blackman, R. A., Blanchard, J. R. Ferbracke, J. E., Moore, D. C., Somerville, H. J., Whitehead, A., Wilkinson, $T$ (1984). Environmental effects of the use of oil-based drilling muds in the North Sea. Mar. Pollut. Bull. 15: 363-370

Davies, J. M., Bedborough, D. R., Blackman, R. A. A., Addy, J. M., Applebee, J. F., Grogan, W. C., Parker, J. G. Whitehead, A. (1989). Environmental effect of oil-based mud drilling in the North Sea. In: Engelhardt, F. R., Ray, J. P., Gillam, A. H. (eds.) Drilling wastes. Elsevier, London, p. $59-90$

Gage, J. (1966). The life histories of the bivalves Montacuta substriata and Montacuta ferruginosa, 'commensals' with spatangoids. J. mar. biol. Ass. U.K. 46: 499-511

Gray, J. S. (1982). Effects of pollutants on marine ecosystems. Neth. J. Sea Res. 16: 424-443

Gray, J. S., Clarke, K. R., Warwick, R. M., Hobbs, G. (1990). Detection of initial effects of pollution on marine benthos: an example from the Ekofisk and Eldfisk oilfields, North Sea. Mar. Ecol. Prog. Ser. 66: 285-299

Groenewoud, H. van het (1991). Monitoring offshore installations on the Dutch continental shelf; a study of monitoring techniques for the assessment of chemical and biological effects of the discharges of drilling muds (1987-1988). TNO-Rapp. R 90/380. Netherlands Organisation for applied scientific research (TNO), Den Helder, The Netherlands, $96 \mathrm{pp}$

Jongman, R. H. G., Ter Braak, C. J. F., van Tongeren, O. F. R (1987). Data analysis in community and landscape ecology. Pudoc, Wageningen

Kingston, P. F. (1987). Field effects of platform discharges on benthic macrofauna. In: Hartley, J P., Clark, R. B. (eds.) Environmental effects of North Sea oil and gas developments. Proc. of a Royal Society Discussion Meeting, 19 and 20 February 1986. Royal Society, London, p. $545-565$

Levell, D., Rostron, D., Dixon, I. M. T. (1989). Sediment macrobenthic communities from oil ports to offshore oilfields. In: Dicks, B. (ed.) Ecological impacts of the oil industries. Wiley, London, p. $97-134$

Matheson, I., Kingston, P. F., Johnson, C. S., Cribson, M. J. (1986). Statfjord field environmental study. In: Proc. Conf on oil based drilling fluids, Trondheim, Feb. 1986. NIVA, Oslo, p. 3-16

Mulder, M., Lewis, W. E., van Arkel, M. A. (1987). Effecten van oliehoudend boorgruis op de benthische fauna rond mijnbouwinstallaties op het Nederlands Continentaal Plat.-NIOZ, Ecologisch Onderzoek Noordzee en Waddenzee: Boorspoeling 1, NIOZ-rapport 1987-3. NIOZ, Texel, The Netherlands, $60 \mathrm{pp}$.

Mulder, M., Lewis, W. E., van Arkel, M. A. (1988). Biological effects of the discharges of contaminated drill-cuttings and water-based drilling fluids in the North Sea. NIOZ, Ecologisch onderzoek Noordzee en Waddenzee. Boorspoeling II. Report 1988-3: 1-126. NIOZ, Texel, The Netherlands

Pearson, T H., Rosenberg, R. (1978). Macrobenthic succession in relation to organic enrichment and pollution of the marine environment. Oceanogr. mar. Biol. Ann. Rev. 16: $229-311$

Pearson, T. H., Gray, J. S., Johannesen, P. J. (1983). Objective selection of sensitive species indicative of pollutioninduced change in benthic communities. 2. Data analyses. Mar. Ecol. Prog. Ser. 12: 237-255

Reiersen, L. O., Gray, J. S., Palmork, K. H., Lange, R. (1989). Monitoring in the vicinity of oil and gas platforms. Results from the Norwegian sector of the North Sea and recommended methods for forthcoming surveillance. In: Engelhardt, F. R., Ray, J. P., Gillam, A. H. (eds.) Drilling wastes. Elsevier, London, p. 91-118

Sokal, R. R., Rohlf, F. J. (1981). Biometry. W. H. Freeman \& Co., San Francisco 